Resumen: Estableciendo un paralelismo con los postulados de Lev Vigotsky, considerado precursor del constructivismo social, el presente artículo se plantea indagar sobre la historia y la evolución del videoarte para proponerlo como herramienta educativa de lectura e interpretación de la realidad que les permita a los estudiantes crear una obra de arte audiovisual como respuesta a una situación problemática dada.

Desde sus comienzos, el videoarte nació como forma de expresión artística crítica de la sociedad política y cultural de su época, los sesenta. Los videastas vanguardistas se apoderaron de la herramienta para hacerse de un discurso audiovisual a partir del cual pudieran decir su palabra. Entonces, como forma de expresión, el videoarte les permitirá a los estudiantes hacer una lectura crítica de su propia realidad y comunicar un punto de vista sobre la misma, explicitando de forma audiovisual el proceso de construcción del conocimiento.

Además, por considerarse lo audiovisual como un discurso universal, la indagación buscará dilucidar si el videoarte puede funcionar como puente que vuelva a conectar a las dos generaciones divididas por el cambio de milenio y la era digital: los nativos digitales y los inmigrantes digitales.

Finalmente, el objetivo del trabajo será investigar en la historia del videoarte la producción discursiva de los videastas, en especial la obra de Nam June Paik y el grupo Fluxus para construir, a partir de este análisis, una herramienta educativa idónea, indagando en el uso de las nuevas tecnologías en educación, sobre todo las que conciernen al diseño multimedial y al discurso audiovisual.

Palabras Claves: constructivismo social - educación - era digital - inmigrantes y nativos digitales - net.art - tecnologías de la información y la comunicación - videoarte.

[Resúmenes en inglés y portugués en las páginas 93-94]

${ }^{(*)}$ Licenciado en Enseñanza de las Artes Audiovisuales (UNSAM, 2008). Realizador Audiovisual (CIEVYC, 2005). Crítico de Cine (EL AMANTE/Escuela, 2006). Profesor de la Universidad de Palermo en el área Audiovisual de la Facultad de Diseño y Comunicación. Coordinador del área Redes Sociales de la Facultad e integrante del equipo de docentes del Programa Tutorías. 


\section{El videoarte como herramienta pedagógica}

Con la aparición de las cámaras de video hogareñas a fines de la década de los sesenta, tecnología fácilmente accesible para todos, el lenguaje de las imágenes en movimiento se modificó sustancialmente originando nuevos productos audiovisuales bien distantes del viejo cinematógrafo, e incluso la joven televisión: el videoclip y el videoarte. Ambos discursos marcaron caminos totalmente diferenciados entre sí: el videoclip se volvió un producto de consumo masivo que se ofrecía como medio de promoción para el mercado de la música con variaciones mínimas y ligadas, casi siempre, al estilo musical propuesto, y el videoarte, una forma artística de vanguardia que releía los manifiestos que otros habían comenzado a escribir en las primeras décadas del siglo veinte a través de una cámara de video.

Hoy, a cincuenta años de este acontecimiento, al menos tres factores sustanciales, la era digital, Internet y las nuevas tecnologías, exigen pensar el discurso audiovisual desde otra óptica, poniendo en jaque el concepto de videoarte y obligando a dialogar a la tecnología de otros tiempos con los nuevos aparatos. Con la masificación de las cámaras de video a niveles astronómicos, replicadas y mejoradas en cada nuevo dispositivo móvil que aparece en el mercado, la popularidad de las redes sociales ligadas, entre otras cuestiones, al intercambio audiovisual y, sobre todo, la constante evolución de lo digital, es indispensable la transformación del discurso para que cada vez que se hable de videoarte no se piense en videocaseteras y televisores de tubo, para que sea posible una nueva revolución artística. Algo similar ocurre en los terrenos de la educación. El quiebre generacional producto del cambio de milenio enfrenta a los llamados nativos digitales, según el término acuñado por Marc Prensky, con los inmigrantes digitales e, incluso, los excluidos digitales. Así, un docente que experimentó, o no, todo el proceso de cambio de la tecnología debe enseñarle a un niño, o a un adolescente, que nació conectado. Entre ambos cortes generacionales las distancias son infinitas y las posibilidades de comunicación se hacen casi imposibles, a menos que existan mediadores tecnológicos intergeneracionales. Entonces, el presente trabajo pretende analizar la evolución del videoarte como herramienta expresiva, y su transformación en el entorno digital, para proponerlo como posible solución a este problema de la educación contemporánea.

\section{La historia del arte o la historia de la tecnología}

La historia del arte, sus modificaciones más o menos sustanciales y, sobre todo, sus revoluciones, nacieron, en la mayoría de los casos, por un cambio de concepción del mundo que, a su vez, vino acompañado de la aparición de una nueva tecnología o la modificación de una tecnología ya existente. Desde el descubrimiento del fuego o la rueda hasta la creación del cinematógrafo a finales del siglo diecinueve, los artistas encontraron en cada una de estas nuevas herramientas una forma propicia para decir su palabra y, por ende, hacer su arte. El fuego les permitió sobrevivir a la oscuridad de la noche pero también a imprimir imágenes en las paredes de las cuevas, la imprenta le dió permanencia en el tiempo a las palabras pero además creó nuevas formas de expresión artística y, finalmente, las imágenes en movimiento, no solamente impulsaron una nueva forma de entretenimiento sino que 
sirvieron a toda una camada de artistas para producir su discurso desde el medio que ellos consideraron más propicio. Los soviéticos descubrieron en el montaje el aparato expresivo ideal para su propaganda política, los franceses y españoles jugaron con el cinematógrafo recreando sus propios sueños y los alemanes le dieron vida a la pesadilla de la guerra en un contraste de sombras e imágenes en movimiento. Entonces, era de esperarse que el descubrimiento de la televisión en la década del cincuenta produjera una modificación sustancial en la forma de comunicarse así como también una nueva manera de hacer arte. El video, tecnología desarrollada durante los sesenta por primera vez para los sistemas de televisión, es la tecnología de la captación, grabación, procesamiento, almacenamiento, transmisión y reconstrucción por medios electrónicos digitales o analógicos de una secuencia de imágenes que representan escenas en movimiento. Etimológicamente la palabra video proviene del verbo latino video, vides, videre, que se traduce como el verbo 'ver'. La cámara de video, al igual que la cinematográfica tiene elementos fotosensibles. Sin embargo, la lectura y el procesamiento de las imágenes es diferente, abaratando los costos y volviendo a la nueva tecnología un instrumento popular, fácilmente accesible para todos. Cuando la cámara de video apareció en el mercado en los sesenta, rápidamente los artistas descubrieron en esta nueva herramienta el medio necesario para expresar sus ideas y nació el videoarte.

\section{Nam June Paik y la deconstrucción del aparato televisivo}

Nam June Paik es considerado por muchos como 'el padre del videoarte'. Nació en Seúl y a los 18 años huyó a Tokio tras el inicio de la Guerra de Corea. Comenzó sus estudios en arte y enseguida se enamoró de la estética occidental. Cuestionando al arte como actividad meramente profesional y cuestionando, sobre todo, el concepto de belleza, Paik integró Fluxus, un grupo de artistas japoneses que realizaban arte de acción o happenings. Las preocupaciones de Paik, entre las que se encontraba el lema de Fluxus "dejar fluir la vida cotidiana para resignificarla como obra de arte”, eran compartidas por los otros integrantes del movimiento, Wolf Vostell, Joseph Beuys, Alan Kaprow, John Cage y Yoko Ono.

Una de las grandes paradojas del videoarte es que su historia se inicia algún tiempo antes que la cámara de video estuviera disponible entre los artistas. De hecho, las primeras obras de la historia del videoarte no incluyen al video como medio. Si bien se había experimentado previamente, y en varias ocasiones, con la imagen electrónica, la muestra Exposition of Musik / Electronic Television del grupo Fluxus, donde Paik acciona con monitores de televisión, se convirtió en el primer exponente del videoarte, forma creativa que pronto se trasladaría a su terreno más fértil: los Estados Unidos. Corría, entonces, marzo de 1963. El concepto fundamental trabajado por Paik, y el resto de los artistas del grupo Fluxus, era una evidente y violenta postura crítica respecto a la televisión. Como había ocurrido con el cine en sus primeras décadas de vida, los artistas de los sesenta veían al medio televisivo como el principal enemigo de la cultura, como el más claro exponente de la manipulación ideológica sobre la que se sustentaba la sociedad de masas. Entonces, utilizaron el videoarte, pariente directo de la televisión, para evidenciar el proceso por el cual los medios masivos irrumpían en la masa cosificándola. 
La primera exposición del grupo Fluxus en la Galería Parnass, en Alemania, presentó trece televisores cuyas imágenes se mostraban distorsionadas, manipulando los circuitos electrónicos de los aparatos. Estas imágenes abstractas buscaban representar cómo los medios de comunicación, y más precisamente la televisión, distorsionan la realidad, manejando el proceso por el cuál el pueblo accede a la información.

Más tarde, Paik redobló su apuesta añadiendo a las imágenes de los aparatos segmentos de televisión pregrabados, intensificando su postura crítica respecto a ellos. Dentro de Fluxus, vale rescatar la obra de Wolf Vostell que, en mayo de 1963, realizó un evento en Nueva York en el que enterró un televisor encendido atado con un alambre de púas. Literales y salvajes, directos y terriblemente expresivos, los integrantes del grupo no se limitaron a lo estético sino que problematizaron sobre la percepción y la desproporción sensorial provocada por las extensiones tecnológicas, sobre todo, la televisión. "La televisión nos ha atacado durante toda la vida", declaró Nam June Paik durante una entrevista, "es hora de que le devolvamos el golpe. Ahora haremos nuestra propia televisión" (Mancini, 2006). En todos los casos, el arte del grupo Fluxus buscó la experiencia con el aparato y la reapropiación del medio a través del happening y el pensamiento-acción.

Estados Unidos, y más precisamente la ciudad de Nueva York, se convirtió en el terreno propicio para el nacimiento de nuevos videoartistas que acompañaron la producción de Paik cuando se trasladó a Norteamérica. En 1965, el artista coreano realizó su primera exposición individual denominada simplemente Electronic art. Una de sus principales instalaciones La luna es la televisión más antigua, compuesta por 12 televisores en silencio, consistía en mostrar en cada pantalla una fase lunar diferente. En su plan de vanguardia, y poniendo en crisis las categorías canónicas del arte, en lugar de proyectar imágenes de la luna, se le ocurrió reemplazarlas por manipulaciones mediante un imán del tubo de rayos catódicos del aparato.

Fue la exploración artístico-tecnológica la que llevó a Nam June Paik a combinar todas las posibilidades que le ofrecía la ciencia con el arte y no resulta extraño descubrir que muchos relatos sobre la vida y obra del artista coreano describen su estudio como un taller de reparaciones electrónicas con varios meses de retraso en los pedidos. En toda su producción se revela una actitud humorística e irreverente respecto a la pantalla de televisión, entendiéndola como medio específico y objeto que posee cualidades estéticas y expresivas propias.

Con la experimentación en la imagen electrónica-audiovisual y esta definida aversión hacia el aparato televisivo, faltaba un único ingrediente para que, finalmente, el videoarte se formara en su máxima expresión: el uso de la tecnología del video (la primera cámara de video portátil para consumo popular salió a la venta en 1965).

De la misma forma que George Méliès, encantado con el cinematógrafo de los Hermanos Lumière, les compró su aparato luego de la primera proyección en el Salon Indien du Gran Café, el 28 de diciembre de 1895, Nam June Paik vió en la cámara de video portátil su herramienta artística y, ni bien salió a la venta, se transformó en el primer artista en adquirir uno de estos aparatos con fines estéticos y artísticos. El universo audiovisual, así como el universo del arte en general, está plagado de esas pequeñas anécdotas que envuelven a la historia bajo un velo de misterio. Cuenta la leyenda que yendo a su taller, después de haber comprado la cámara de video, el taxi en el que viajaba quedó atrapado en un 
embotellamiento causado por la visita del Papa a la ciudad de Nueva York. Paik filmó el acontecimiento y esa misma noche lo presentó en el Café a Go-Go ante un grupo de amigos. Nacía así la primer obra de videoarte.

Finalmente, con el transcurrir del tiempo, los realizadores comenzaron a preocuparse por definir las características específicas del video como medio, aquellas que lo distinguen de otros medios, dando lugar a verdaderas obras experimentales.

\section{Evolución: de la televisión a la sociedad de la información}

La descripción que hace J. R. Perez Ornia en El videoarte de vanguardia acerca de Nam Jun Paik es exacta:

El inventor del videoarte fue un músico que adornaba sus instrumentos con todo tipo de quincallería, que rompía violines o extraía música de los objetos, que introducía en sus composiciones actos heterodoxos y provocativos, como romper huevos o cortarle la corbata a John Cage (La Ferla, 1996).

En este contexto, no resulta nada extraño que, años más tarde, en la década de los ochenta, luego de haber desarrollado todo un discurso crítico en torno a la televisión, Paik se anticipara culturalmente a la llegada de Internet y se convirtiera, nuevamente, en el primer artista en utilizar satélites en performances de alcance mundial.

El objetivo del artista coreano, luego arraigado en los Estados Unidos, siempre fue el mismo: crear arte con materiales nuevos. Así, volvió a experimentar con el elemento temporal de las artes populares, el ritmo, tan importante en videoarte, pero a través de este nuevo medio, el satélite, que rompía con las barreras comunicacionales como nunca antes se había hecho. Claro que detrás de la experimentación, detrás del juego con el nuevo aparato, había un segundo objetivo mucho más firme en la mente de Paik. Si en el uso de los televisores buscaba provocar un subrayado sobre su crítica a la televisión como medio masivo, y popular, de comunicación, en este caso, los satélites acentuarían sus propósitos pacifistas. Quizás no sea casual que se le atribuya a Nam June Paik ser el primero en utilizar el término de Sociedad de la información porque, en sus declaraciones, advierte los procesos simbólicos contemporáneos sin alejarse de la democratización expresiva para pensar las nuevas tecnologías.

"El sintetizador de video fue de algún modo el comienzo de Internet porque daba la posibilidad de crear contenido mediático por uno mismo" explicó Nam June Paik en una entrevista realizada por teléfono con el periodista alemán Tilman Baumgärtel en 2001.

Ya se está hablando de un híbrido, mitad computadora y mitad televisor, que puede recibir unos cuantos cientos de estaciones de televisión. Si eso sucede, pronto podré comprar mi propia licencia y emitir mi videoarte desde una súper computadora a través de esa estación todos los días (Mancini, 2006). 
Lamentablemente, Paik no llegó a ver su deseo plasmado en sitios como Vimeo o Youtube. Sin embargo, sus dichos y su carrera, donde el arte se comprometía a evolucionar junto con la tecnología, decantaron en una nueva forma de producción artística que se concibió en la década de los noventa y explotó estética y creativamente en el nuevo milenio: el net.art. La gran red llega a donde ni la televisión, ni los satélites lograron llegar. Rompe, definitivamente, con las barreras comunicacionales e idiomáticas y desciende, en tiempo real, en infinidad de dispositivos que hacen de la Internet la nueva y perfecta excusa para repensar el arte. Pero, sobre todo, Internet permite desarrollar un proyecto colaborativo con gente de cualquier parte del planeta transformándose en algo así como, como lo metaforizaría Paik, un cuarteto de cuerdas. "Una vez que la fibra óptica vaya alrededor del mundo la Internet será más excitante" (Mancini, 2006). Leer o escuchar a Nam June Paik es realizar un viaje hacia el futuro, casi como leer a Jules Verne, sabiendo que hay mucho más de ciencia que de ficción en su relato y en sus ideas.

\section{arte.en.red y cibercultura}

El arte llegó a Internet y se llamó así mismo net.art. El arte en red se refiere al género de producciones artísticas realizadas ex profeso en y para Internet. Como movimiento específico su origen fue a fines de la década de los noventa coincidiendo con el desarrollo de la World Wide Web. Sin embargo, en tanto género, el arte en red continúa desarrollándose en la actualidad siendo una de las formas de arte interactivo habilitadas por los soportes digitales y las prácticas comunicativas generadas por ellos.

Primero fue el cinematógrafo y el montaje, luego la televisión, las computadoras y los satélites, y finalmente, los dispositivos móviles y el ciberespacio. La denominación net.art designa las prácticas artísticas que apuntan a una experiencia estética específica que ubica a la Internet como soporte de la obra, dialogando o explorando las prácticas comunicativas en la cibercultura.

Pero ¿qué es esta nueva cultura? ¿cómo funciona esta nueva manera de comunicarnos? Fueron las tecnologías de la información y la comunicación (también denominadas TICs) las que generaron la última revolución del siglo veinte que modificó la manera de acceder, apropiarse y transmitir la información, concibiendo un nuevo desarrollo social, político y económico en torno al ciberespacio, Internet y la World Wide Web, y un nuevo lenguaje universal: el digital.

Es Derrick De Kerckhove quien define en su libro Inteligencias en conexión: Hacia una sociedad de la web las tres condiciones que existen detrás de la cultura digital o la cibercultura: la interactividad, la hipertextualidad y la conectividad. Siendo la interactividad la relación entre la persona y el entorno digital definido por el hardware que los conecta; la hipertextualidad, el acceso interactivo a cualquier cosa desde cualquier parte; $y$, finalmente la conectividad, la tendencia humana a juntar lo que está separado, mediante un vínculo o relación. Internet, gracias a su estructura hipertextual ha enlazado el contenido almacenado a su comunicación, convirtiéndose en el medio conectado por excelencia que vuelve explícita y tangible la interacción humana y potencia la colaboración entre las personas. 
Todo este panorama de potencialidades tecnológicas converge, según De Kerckhove, en un espacio para nuevas variedades de estructuras psicológicas que van a conducir indefectiblemente en la aparición de una sensibilidad conectada, una nueva sociología (De Kerckhove, 1999). El desarrollo de las tecnologías de la información, y la concepción de esta nueva sensibilidad digital, revivió el concepto de aldea global de Marshall Mac Luhan y dió un nuevo impulso al proceso de la globalización, obligando a repensar cada uno de los hechos significativos que integran a la cultura, entre ellos, el arte.

En este contexto se concibe, entonces, el net.art, cuya característica fundamental es el uso de los recursos de la red para producir la obra, una obra que se realizará y compartirá en línea.

\section{De la manifestación estética al lenguaje artístico}

El arte, en sus más diversas expresiones, es una actividad eminentemente social, que se hace presente en la vida cotidiana del hombre y la mujer. El ser humano vive rodeado de manifestaciones artísticas en pequeña, mediana o gran escala, en su hogar, en su lugar de trabajo, o en la calle. Una fotografía del Riachuelo retocada digitalmente y compartida en Internet, un ramo de flores marchitas en el lugar indicado, o incluso un plato de comida recién elaborado, pueden convertirse en la mente de los espectadores en manifestaciones estéticas que lo conmuevan.

Lo artístico es un aspecto central de la vida del ser humano que lo ayuda a diferenciarse del resto de los seres vivos ya que él es el único capaz de producirlo y disfrutarlo, ocupando un lugar destacado para todos porque es parte de la experiencia pública y porque, a través de él, se manifiesta la cultura.

La actividad artística, múltiple e integradora, cumple diversas funciones a lo largo de la historia y a lo ancho del planeta, siendo, quizás, las más significativas, su capacidad de comunión, su posibilidad de reflejar la vida y la realidad reflexionando sobre ella, y el desarrollo de una actitud creadora en el ser humano, base de todo nuevo descubrimiento científico que ayuda a satisfacer y mejorar su subsistencia.

Hoy en día, varios teóricos de la historia de lo estético, coinciden en entender al arte como un lenguaje, plasmado en la obra producida. La forma de este objeto artístico, y sobre todo su proceso de elaboración, comunican su contenido espiritual volviéndolo más o menos explícito. El hombre y la mujer por medio de este objeto satisfacen sus necesidades estéticas de conocimiento pero a su vez manifiestan su ideología, su subjetividad, su visión de la realidad, objetivando el vínculo que existe entre sus personalidades, la estructura cultural de su época y el medio social al que pertenecen que de alguna manera los condicionan, pero al que pueden llegar a modificar.

Si bien algunos de estos mensajes implican un acceso directo a la comunicación, gracias a los avances multimediales y comunicacionales, de los que no se puede escapar, la brecha entre el significado y el significante se ha ido alejando cada vez más, implicando otros niveles de lectura que requieren ser aprendidos para poder ser interpretados. En este aspecto, siendo el arte un medio de conocimiento que, por un lado, le permite al ser humano analizar e interpretar el mundo en un obra y, por el otro, utilizar diferentes lenguajes sim- 
bólicos para realizar sus propias producciones artísticas y comunicarse, y estando rodeados de múltiples manifestaciones estéticas que es necesario interpretar, resulta paradójico que aún hoy lo artístico no se haya convertido en una de las herramientas esenciales de los procesos de enseñanza y aprendizaje contemporáneos.

Los siguientes párrafos buscarán, entonces, convertirse en un manifiesto reflexivo sobre el papel del arte en la educación pero, sobre todo, en la inclusión del videoarte como herramienta expresivo-reflexiva que conduzca a los estudiantes de diferentes niveles a la construcción de una mirada estético-crítica sobre el mundo que lo rodea, las producciones mediático-comunicacionales contemporáneas e, incluso, una autorreflexión profunda. Finalmente, se indagará en la brecha generacional entre los docentes inmigrantes o excluidos digitales y sus estudiantes nativos conectados proponiendo al videoarte como puente que lleve a ambos sujetos a mejorar su comunicación y, por lo tanto, el proceso de enseñanza-aprendizaje.

\section{Del arte y la educación}

Lev Vigotsky, psicólogo ruso de origen judío, uno de los más destacados teóricos de la psicología del desarrollo, planteó en sus estudios que la relación del individuo con su realidad exterior no es simplemente biológica, ya que a través de la utilización de instrumentos adecuados puede extender su capacidad de acción sobre esa realidad (Vigotsky, 1982). Algunos de estos instrumentos, las herramientas, son reales y palpables. Otros en cambio, como el lenguaje, son de origen simbólico. A estos últimos, Vigotsky les atribuye un lugar especial porque les permiten al individuo actuar sobre su propia realidad y ponerse en contacto con el pensamiento de los demás y con la cultura, que influyen recíprocamente sobre él. El pensamiento, entonces, tiene un origen social, es consecuencia de una relación social y no el resultado del despliegue de las posibilidades de un individuo aislado.

Así, el lenguaje, y a través de él la cultura, tienen una influencia decisiva en el desarrollo y las relaciones sociales potencian enormemente las posibilidades de aprendizaje. Lev Vigotsky introduce aquí el concepto de zona de desarrollo próximo para explicar la distancia entre el nivel de desarrollo efectivo del alumno (aquello que es capaz de hacer por sí solo) y el nivel de desarrollo potencial (aquello que sería capaz de hacer con la ayuda de un docente o un compañero más capaz).

Pero ¿cuál es el papel que se le podría dar al arte en todo este asunto de la educación? ¿Cómo puede influir una experiencia artística en la zona de desarrollo próximo de un estudiante? Y, finalmente, ¿cuál es la modificación que podría aportar el videoarte, o las tecnologías de la información y la comunicación, en el proceso de enseñanza-aprendizaje? En educación, el arte es concebido como una disciplina tradicional que nace en la academia de la Grecia Clásica y llega a nuestros días con la proliferación de carreras universitarias que estudian lo estético desde alguna forma artística. Sin embargo, por mucho tiempo, la Educación Artística ha ocupado un lugar periférico en los diseños curriculares en relación con otras áreas que se consideraban centrales. En Escuela de Rock (School of Rock, Richard Linklater, 2003), film norteamericano que narra la historia de un músico de 
rock que en bancarrota se hace pasar por maestro de escuela, el protagonista expresa su opinión sobre los educadores diciendo “Those who can’t do, teach. And those who can't teach, teach gym” (“Aquellos que no pueden hacer, enseñan. Y aquellos que no pueden enseñar, enseñan gimnasia"). Más allá de la cuota de humor que otorga la frase expresada por Jack Black, que incluso es guiño de una frase de Woody Allen en su film Annie Hall (1977), evidencia el rol del docente en la educación contemporánea y, sobre todo, el rol del docente de alguna disciplina artística.

Estas desvalorizaciones educativas se deben, en parte, a la modificación que produjo el pensamiento positivista de la mirada del hombre sobre el mundo, y sobre el arte. La filosofía positivista asumió ante el conocimiento una actitud cientificista relegando a otros objetos del saber, como son los procesos psicológicos, ideológicos, culturales, sociales y artísticos, que no podían obtenerse a través del método científico experimental y por lo tanto no alcanzaban el grado de cientificidad requerido, a un lugar secundario en la educación. Es verdad que el siglo veinte trajo consigo una serie de transformaciones en torno a la visión del hombre sobre su propio mundo. Sin embargo, el prejuicio por la educación artística, tan alejada de lo científico, aún permanece latente. Es el deber de los educadores, y la propuesta de este artículo, proponer diferentes caminos para que la mirada respecto al rol del arte en educación se modifique finalmente.

Como bien lo describe Herbert Read en Educación por el arte, no se trata de convertir a todos los estudiantes en artistas sino de acercarles los lenguajes de las disciplinas artísticas que les permitan nuevos y distintos modos de comunicación y expresión, desarrollando sus competencias individuales a través de la sensibilización, la experimentación, la imaginación y la creatividad (Read, 1982).

Todos los seres humanos poseen capacidad para la creación. Pero sin aprendizaje no hay creatividad posible porque, el hecho creativo, es el resultado de una serie de simbolizaciones, vivencias y asimilaciones de conocimientos, una síntesis de componentes cognitivos, afectivos, sociales e imaginativos que hay que saber producir e interpretar. Vigotsky denomina a esta capacidad del ser humano como la actividad creadora.

Llamamos actividad creadora a toda realización humana creadora de algo nuevo, ya se trate de reflejos de algún objeto del mundo exterior, ya de determinadas construcciones del cerebro o del sentimiento que viven y se manifiestan sólo en el propio ser humano (Vigotsky, 1982).

La actividad creativa se relaciona directamente con la variedad y la riqueza de la experiencia acumulada por lo que es necesario ampliar la experiencia de los estudiantes si se quiere brindar una sólida base para su actividad creativa. "La finalidad del arte en la educación debería ser idéntica a la finalidad de la educación misma”, insiste Read en sus postulados. "En última instancia, no hago distinciones entre ciencia y arte, salvo como métodos, y creo que la oposición entre ambas en el pasado se ha debido a una concepción limitada de ambas actividades" (Read, 1982). El arte es representación y la ciencia, explicación de la misma realidad.

El punto de partida para la nueva educación debería ser, entonces, la sensibilidad estética. 
La información manipulada de forma tradicional no resulta atractiva para los estudiantes de hoy. El aprendizaje memorístico, en presencia de las computadoras y la conexión a Internet, pierde todo sentido (si es que alguna vez lo tuvo). Entonces, desde Vigotsky hasta Read, la propuesta es introducir lo estético como herramienta educativa para así ampliar la experiencia de los estudiantes, rompiendo sus esquemas mentales y logrando, finalmente, su aprendizaje significativo.

Aún así, la educación contemporánea presenta un obstáculo más: el quiebre generacional producido por la era digital y la aparición de la Internet.

\section{Rompiendo barreras a través del videoarte}

Según el estudio realizado por Mark Prensky para la elaboración de su artículo Nativos e Inmigrantes Digitales un estudiante universitario invierte en promedio menos de cinco mil horas de lectura durante su vida universitaria mientras que pasa alrededor de veinte mil horas viendo televisión, jugando a los videojuegos o conectado a la gran red. Los docentes de estos estudiantes que nacieron conectados se formaron en una época en la que la televisión era sólo un divertimento más a la que se accedía una vez que se había concluido con las actividades educativas.

Está claro que los tiempos cambiaron. Que la modificación de las experiencias llevó indefectiblemente a una modificación en las estructuras mentales de los educandos produciendo así el quiebre generacional, y la falta de un lenguaje común, con sus educadores. Prensky denomina a los primeros como nativos digitales puesto que todos han nacido y se han formado utilizando la particular lengua digital de los videojuegos, la televisión e Internet; mientras que a los adultos nacidos en otra época los separa entre inmigrantes digitales, aquellos que buscan el acceso a la nueva tecnología obligados por la necesidad de estar al día, y excluidos digitales, aquellos que, finalmente, no supieron cómo adaptarse y se quedaron afuera.

La realidad es inminente: los inmigrantes y los excluidos digitales que se dedican a la enseñanza están empleando una lengua obsoleta (la propia de la era pre-digital) para instruir a una generación que controla lo nuevo a la perfección. Lo único que comparten es el sentimiento de angustia por escuchar del otro una lengua que desconocen, como un extranjero que, sin saber chino, entra a un restaurante en Shanghái pidiendo desesperadamente un vaso de agua. Los estudiantes están sedientos de conocimiento y sus docentes le brindan vasos con arena.

Prensky define las diferencias entre nativos e inmigrantes digitales diciendo que, los primeros, desean recibir la información de forma ágil e inmediata, se sienten atraídos por una multiplicidad de áreas y por procesos paralelos, prefieren las imágenes a los textos, se inclinan por los accesos al azar (desde hipertextos), funcionan mejor y rinden más cuando trabajan en Red, son conscientes de su crecimiento progresivo satisfaciéndose y siendo recompensados inmediatamente y, finalmente, prefieren instruirse a través del juego y no en el rigor del trabajo tradicional (Prensky, 2010). Por otro lado, los inmigrantes digitales, en la mayoría de los casos, prefieren moverse en zonas conocidas desvalorizando los conocimientos previos de sus estudiantes, negando la evolución. 
¿Es posible el aprendizaje en este terreno? Si se busca el aprendizaje significativo por parte de los estudiantes la respuesta es un rotundo no. Para tender un puente sobre la brecha generacional que produjo la era digital es necesario que los docentes del nuevo milenio aprendan a comunicarse con sus estudiantes a través de una lengua y un estilo común. No se trata de cambiar el significado de lo importante sino, simplemente, abandonar el "paso a paso" por el "ir más rápido", profundizar más aún y hacerlo siempre en paralelo, acceder desde y bajo el azar, etcétera.

Descartando el marco contextual que no impide la apreciación de sus películas, Pixar tiene adeptos de todas partes del globo aún con sus cortometrajes que sin palabras conmueven al mundo por igual. Charles Chaplin hizo reír y emocionar a varias generaciones de procedencias muy diferentes. Finalmente, la escena del hundimiento del Titanic, en la película homónima de James Cameron, no necesita de otras cuestiones que la imagen audiovisual para robar varias lágrimas. El discurso audiovisual, el de las imágenes en movimiento, el del cinematógrafo pero también el del videoarte, es universal y no requiere de grandes conocimientos para ser aprehendido.

Entonces, entre la confusión que se genera en el aula, producto de la falta de un lenguaje común entre docentes y estudiantes, aparece lo audiovisual como puente comunicativo, como experiencia de unión de aquello que fue separado por el cambio de milenio.

Finalmente, dentro del enorme abanico de posibilidades que otorga el universo audiovisual, se destaca el videoarte como uno de los mejores medios para desarrollar un proyecto pedagógico desde la imagen en movimiento que otorgue resultados significativos.

El videoarte, como lenguaje artístico perteneciente al complejo campo de la hipermedia, permite esbozar disparejas entradas temáticas y de interpretación, discurriendo positivamente sobre la capacidad operativa y de razonamiento singular en el aprovechamiento de cada espectador/estudiante (Martínez Gueyraud, 2010).

El autor comparte el deseo de estimular la actitud crítica del estudiante frente al enmascaramiento de la realidad orientándolo hacia la innovación técnica, social y cultural como alternativa ante el conformismo, la repetición o la simple imitación de modelos aplicables. Más que a los estudiantes, inconformistas por naturaleza, sus palabras parecen estar dirigidas hacia los docentes, inmigrantes digitales. El videoarte, al poner en cuestión constantemente las nociones de cambio y renovación "abre la mente de los estudiantes y posibilita un concepto de la realidad que, por una parte, es inabarcable, cambiante y ambigua, y, por otra, es individual y única para cada espectador/estudiante" (Martínez Gueyraud, 2012).

\section{Cierres y nuevas aperturas}

Cuando se habla de videoarte, enseguida aparecen las imágenes de una videocasetera, un televisor de tubo y un VHS. Sin embargo, la evolución de las tecnologías ha dado como resultado una expansión del concepto al terreno digital mucho más relacionada con los tiempos que corren. 
Los objetivos del presente trabajo estaban direccionados a proponer al videoarte como una posible herramienta pedagógica que rompiera con la barrera generacional producida por el cambio de milenio. Sin embargo, en el desarrollo de la investigación, surgieron nuevos caminos que obligaron a ampliar la mirada. Hoy la propuesta es diferente. Ya no se trata de encontrar un lenguaje común entre docentes y estudiantes sino obligarlos, a ambos personajes involucrados en el proyecto de enseñanza-aprendizaje, a adquirir nuevas capacidades que les permitan observar el mundo que los rodea a través de una mirada crítica. Pero para ello se debe interactuar con el medio, con la herramienta.

Paradójicamente, la investigación concluye en la teoría. No por falta de tiempo o de recursos sino como una decisión del autor de involucrar a sus lectores en la experiencia propia, incentivándolos a utilizar la herramienta en sus clases cualquiera sea el área de la que provengan. Es una cuestión de confianza. Porque, en palabras de Earl Gary Stevens, escritor estadounidense, "la confianza, como el arte, nunca proviene de tener todas las respuestas sino estar abiertos a todas las preguntas".

\section{Referencias Bibliográficas}

Kerckhove De, D. (1999). Inteligencias en conexión. Hacia una sociedad de la web. Barcelona: Gedisa.

Mancini, P. (2006). Nam June Paik, el padre del videoarte. Buenos Aires: educ.ar. Recuperado de http://portal.educ.ar/debates/protagonistas/arte-cultura/nam-june-paik-el-padredel-videoarte.php

Martínez Gueyraud, A. (2010). El videoarte como nuevo agente didáctico del diseño contemporáneo o los adiestramientos de transposición entre irrealidades y realidades. En Actas de Diseño No 8. IV Encuentro Latinoamericano de Diseño. Buenos Aires: Centro de Estudios en Diseño y Comunicación. Universidad de Palermo.

Prensky, M. (2010). Nativos e Inmigrantes Digitales. Madrid: Institución Educativa SEK. Recuperado de www.marcprensky.com/writing/Prensky-NATIVOS\%20E\%20INMIGR ANTES\%20DIGITALES\%20(SEK).pdf

Read, H. (1982). Educación por el arte. Barcelona: Ediciones Paidós Ibérica.

Vigotsky, L. S. (1982). La imaginación y el arte en la infancia. Buenos Aires: Akal.

\section{Bibliografía}

Kerckhove De, D. (1999). Inteligencias en conexión. Hacia una sociedad de la web. Barcelona: Gedisa.

Mancini, P. (2006). Nam June Paik, el padre del videoarte. Buenos Aires: educ.ar. Recuperado de http://portal.educ.ar/debates/protagonistas/arte-cultura/nam-june-paik-el-padredel-videoarte.php

Martínez Gueyraud, A. (2010). El videoarte como nuevo agente didáctico del diseño contemporáneo o los adiestramientos de transposición entre irrealidades y realidades. En Actas de Diseño No 8. IV Encuentro Latinoamericano de Diseño. Buenos Aires: Centro de 
Estudios en Diseño y Comunicación. Universidad de Palermo.

Perez Ornia, J. R. (1996). El videoarte de vanguardia. En La Ferla, J. (comp.). La revolución del video. Buenos Aires: Libros del Rojas.

Prensky, M. (2010). Nativos e Inmigrantes Digitales. Madrid: Institución Educativa SEK. Recuperado de www.marcprensky.com/writing/Prensky-NATIVOS\%20E\%20INMIGR ANTES\%20DIGITALES\%20(SEK).pdf

Read, H. (1982). Educación por el arte. Barcelona: Ediciones Paidós Ibérica.

Vigotsky, L. S. (1982). La imaginación y el arte en la infancia. Buenos Aires: Akal.

Summary: Drawing a parallel with the postulates of Lev Vygotsky, considered a precursor of social constructivism, this article proposes to investigate the history and evolution of video art as an educational tool that allows students to create a visual art work in response to a given problem situation.

Since its inception in the '60s, video art was conceived as a form of critical artistic expression of political and cultural society. The avant-garde video artists seized the tool for getting a visual discourse from which they could have their own voice. Then, as a form of expression, video art students will allow a critical reading of his own reality and communicate a point of view on it, explaining the visual form of knowledge construction process. In addition, considering the audiovisual as an universal discourse, the research will seek to ascertain whether video art can function as a bridge to reconnect the two generations divided by the turn of the millennium and the digital age: digital natives and digital immigrants. Finally, the aim of this work is to investigate in the history of video art the discursive production of videographers, especially the work of Nam June Paik and the Fluxus group to construct, from this analysis, an ideal educational tool, investigating the use of new technologies in education, especially those concerning the design of multimedia and audiovisual speech.

Keywords: digital age - digital immigrants and digital natives - education - information technology and communication - net.art - social constructivism - video art.

Resumo: A partir do traçado do paralelismo com os postulados de Lev Vigotsky, considerado precursor do construtivismo social, este artigo indaga sobre a história e a evolução do vídeo arte para propô-lo como ferramenta educativa de leitura e interpretação da realidade que permita aos estudantes criar uma obra de arte audiovisual como resposta a uma situação problemática particular.

O vídeo arte nasceu como forma de expressão artística crítica da sociedade política e cultural da sua época, os sessenta. Os videastas vanguardistas apoderaram-se da ferramenta para fazer-se de um discurso audiovisual a partir do qual puderam dizer sua palavra. Então, como forma de expressão, o vídeo arte lhes permitirá aos estudantes fazer uma leitura crítica de sua própria realidade e comunicar um ponto de vista sobre ela, explicitando de modo audiovisual o processo de construção do conhecimento.

Além, por considerar-se o audiovisual como um discurso universal, a indagação procurará 
esclarecer se o vídeo arte pode funcionar como ponte que enlace novamente as duas gerações divididas por o cambio de milênio e a era digital: os nativos digitais e os imigrantes digitais. Finalmente, o objetivo do trabalho será pesquisar na história do vídeo arte a produção discursiva dos videastas, em especial a obra de Nam June Paik e o grupo Fluxus para construir, a partir desta analise, uma ferramenta educativa idônea, indagando no uso das novas tecnologias em educação, sobre tudo as relativas ao design multimídia e ao discurso audiovisual.

Palavras chave: construtivismo social - educação - era digital - imigrantes e nativos digitais - net.art - tecnologias da informação - vídeo arte. 